\title{
Caloric Restriction Enhances Fear Extinction Learning in Mice
}

\author{
Megan C Riddle ${ }^{1,2}$, Morgan C McKenna ${ }^{3}$, Yone J Yoon ${ }^{3}$, Siobhan S Pattwell, ${ }^{3,4}$, Patricia Mae G Santos ${ }^{5}$, \\ B J Casey ${ }^{2,3,4}$ and Charles E Glatt*,3 \\ 'Weill Cornell/Rockefeller/Sloan Kettering Tri-Insitutional MD-PhD Program, Weill Cornell Medical College, New York, NY, USA; \\ ${ }^{2}$ Department of Neurology and Neuroscience, Weill Cornell Medical College, New York, NY, USA; ${ }^{3}$ Department of Psychiatry, \\ Weill Cornell Medical College, New York, NY, USA; ${ }^{4}$ Sackler Institute for Developmental Psychobiology, Weill Cornell Medical College, \\ New York, NY, USA; ${ }^{5}$ Brown University, Providence, Rhode Island
}

\begin{abstract}
Fear extinction learning, the ability to reassess a learned cue of danger as safe when it no longer predicts aversive events, is often dysregulated in anxiety disorders. Selective serotonin reuptake inhibitors (SSRI's) enhance neural plasticity and their ability to enhance fear extinction learning may explain their anxiolytic properties. Caloric restriction (CR) has SSRI-like effects on neural plasticity and anxiety-related behavior. We implemented CR in mice to determine its effects on conditioned-fear responses. Wild type and serotonin transporter (SERT) knockout mice underwent CR for 7 days leading to significant weight loss. Mice were then tested for cued fear learning and anxiety-related behavior. CR markedly enhanced fear extinction learning and its retention in adolescent female mice, and adults of both sexes. These effects of CR were absent in SERT knockout mice. Moreover, CR phenocopied behavioral and molecular effects of chronic fluoxetine, but there was no additive effect of CR in fluoxetine-treated mice. These results demonstrate that CR enhances fear extinction learning through a SERT-dependent mechanism. These results may have implications for eating disorders such as anorexia nervosa (AN), in which there is a high prevalence of anxiety before the onset of dietary restriction and support proposals that in $\mathrm{AN}, \mathrm{CR}$ is a motivated effort to control dysregulated fear responses and elevated anxiety.

Neuropsychopharmacology (2013) 38, 930-937; doi:I0.1038/npp.2012.268; published online 23 January 2013
\end{abstract}

Keywords: caloric restriction; fear learning; fear extinction; serotonin transporter; fluoxetine; anorexia nervosa

\section{INTRODUCTION}

The ability to differentiate cues of danger and safety is critical for survival (LeDoux, 2012). Fear learning is an evolutionarily conserved process that enables an individual to learn danger signals, and then reassess these signals over time to adapt to a changing environment. In cued fear conditioning studies, an association is formed between an aversive, unconditioned stimulus (US) and a co-occurring, neutral conditioned stimulus (CS). Over repeated pairings, the CS takes on the aversive properties of the US such that it can independently elicit a fear response. Fear extinction occurs when, after fear conditioning, the CS alone is presented repeatedly and fear responses to the CS decrease. The ability to reassess cues of danger as safe has been associated with lower subjective experiences of anxiety, and inefficient fear extinction learning is present in a number of anxiety disorders (Graham and Milad, 2011). Because fear extinction learning is an active learning process that requires neural plasticity (Kaplan and Moore, 2011; Sotres-Bayon et al, 2007), genetic and pharmacologic

*Correspondence: Dr CE Glatt, Department of Psychiatry, Weill Cornell Medical College, LC929A, I 300 York Avenue, New York, NY 10065, USA, Tel: + 212746 6723, Fax: + 2127468529 ,

E-mail: ceg2004@med.cornell.edu

Received 20 September 2012; revised I December 2012; accepted 24

December 2012; accepted article preview online 3 January 2013 factors that increase neural plasticity, can enhance fear extinction learning (Mao et al, 2006; Soliman et al, 2010; Sotres-Bayon et al, 2007).

The serotonin transporter (SERT) can modulate neural plasticity including adaptive fear learning. These properties may explain its role in mood and anxiety disorders. Mice with genetic knockout of SERT have impaired retention of fear extinction, as well as increased depression- and anxiety-like behavior (Wellman et al, 2007). Reduced expression of SERT is seen in humans with anxiety disorders (Maron et al, 2004; Murrough et al, 2011; Reimold et al, 2007), and a polymorphism affecting SERT expression in humans has been associated with fear extinction retention, and risk for panic disorder (Gyawali et al, 2010; Hartley et al, 2012). Moreover, the SERTtargeting selective serotonin reuptake inhibitors (SSRI's) enhance fear extinction retention (Karpova et al, 2011).

CR has SSRI-like anxiolytic properties in mice that may also be due to enhanced neural plasticity and fear extinction learning (Yamamoto et al, 2009). In the visual system CR enhances neural plasticity in a manner similar to SSRI's. Both CR and fluoxetine allow adult mice to reestablish binocular vision following early-life monocular deprivation even after the sensitive period for visual plasticity has closed (Maya Vetencourt et al, 2008; Spolidoro et al, 2011).

To assess the effects of CR on adaptive fear responses, we implemented a cued fear learning paradigm in mice. We found that $\mathrm{CR}$ enhances fear extinction learning and 
retention. In contrast, mice lacking SERT do not display enhanced fear extinction learning with CR, suggesting SERT has a crucial role in mediating this effect of CR. We also found that CR phenocopies the effects of fluoxetine on fear extinction learning, and the expression of a SERT mRNA species that we previously associated with decreased anxiety states and enhanced fear extinction retention (Gyawali et al, 2010; Hartley et al, 2012). We discuss how these results may be relevant to anorexia nervosa, an eating disorder characterized by both high levels of anxiety and caloric restriction $(\mathrm{CR})$.

\section{MATERIALS AND METHODS}

\section{Animals}

Pregnant C57BL/6 females were purchased from Charles River, and offspring used for studies with adolescent mice. Adult C57BL/6 mice were purchased from Charles River at postnatal day (P) 60. Breeding pairs of SERT knockout B6.129(Cg)-Slc6a4 ${ }^{t m 1 K p l} / \mathrm{J}$ mice (Bengel et al, 1998) were obtained from the Jackson Laboratory's repository. All B6.129(Cg)-Slc6a4 ${ }^{\text {tm } 1 K p l}$ mice used for testing were from heterozygous crosses, allowing for comparison of wild-type and knockout littermates. Knockout mice were genotyped by Mouse Genotype. Mice received ad libitum (AL) access to food until assignment to diet regimen. Mice were weighed and fed daily within $2 \mathrm{~h}$ of onset of dark cycle. Mice undergoing CR received $60 \%$ of the $\mathrm{AL}$ group's previous day's consumption as described (Yamamoto et al, 2009). Adolescent mice began CR between days P36 and P38. Adult mice began CR when 2-4 months old. Mice remained on the feeding regimen until the termination of testing. Mice were handled following the guidelines of Weill Cornell Medical College's Institutional Animal Care and Use Committee and the National Institutes of Health.

\section{Fluoxetine Treatment}

Fluoxetine dissolved in tap water $(160 \mathrm{mg} / \mathrm{l})$ was provided in the drinking water in light-protected bottles, and changed every 3 days. AL intake led to a dose of $\sim 18 \mathrm{mg} /$ $\mathrm{kg}$ per mouse, reported to produce anxiolytic levels (Chen et al, 2006). Mice began fluoxetine 2 weeks before CR and remained on the drug until study completion.

\section{Fear Conditioning and Extinction}

On day 8 of $\mathrm{CR}$, mice were fear conditioned using a standard mouse shock-chamber (Coulbourn Instruments) in a sound-attenuated box scented with peppermint odor. Mice received three trials of CS tone $(30 \mathrm{~s}, 70 \mathrm{~dB}$, and $5 \mathrm{kHz})$ coterminating with an US footshock $(1 \mathrm{~s}, 0.7 \mathrm{~mA})$ with $30 \mathrm{~s}$ between each CS-US pairing (Soliman et al, 2010). Extinction training occurred 24 and $48 \mathrm{~h}$ after conditioning. In a novel context, a silver metal cylinder scented with limonene $(0.1 \%$ limonene), mice were exposed to 18 unreinforced presentations of the tone at $3 \mathrm{~min}$ intervals (Monfils et al, 2009). Trials were recorded and freezing behavior assessed with FreezeFrame and FreezeView software (Coulbourn Instruments). This protocol resulted in submaximal levels of extinction in AL animals, making the paradigm sensitive to manipulations that would enhance extinction learning.

Freezing behavior was compared between groups for within session extinction learning on day 1 and retention of extinction learning over 2 days of extinction training. For within session extinction, the difference was calculated between tones $2-5$ and $15-18$. The first tone was excluded because many mice displayed escape behavior during this tone, attempting to jump out of the chamber. Although this represents a fearful response, it lowered apparent freezing, thus this time point was eliminated from analysis. For extinction retention, the difference was calculated between tones $2-5$ on day 1 and 1-4 on day 2 . On day 2 of extinction, mice froze in response to the first tone, so this tone was included in analysis. Female animals were randomly tested across the estrous cycle.

\section{Elevated Plus Maze}

Anxiety-like behavior was measured using the elevated plus maze 2 days after the final session of extinction training. For each trial, the mouse was placed on the central platform facing an open arm and behavior recorded for 5 min and analyzed using Ethovision XT software (Noldus) (Yamamoto et al, 2009).

\section{Object Placement}

Mouse behavior was recorded with a digital camera and analyzed with EthoVision XT tracking system (Noldus). On day 8 of $\mathrm{CR}$, adult female mice that had not undergone fear conditioning training were placed in an open field arena, and behavior recorded for $5 \mathrm{~min}$ to determine there was no preference for one specific region. The next day, two identical Lego trees were placed in the northeast and northwest quadrants of the arena; the mouse was placed in the center of the arena and behavior recorded for $5 \mathrm{~min}$, trial 1 (T1). The mouse was placed in a holding cage for $5 \mathrm{~min}$ and the arena and objects cleaned. One object was returned to its previous location, the other moved to the southern end of the box, diagonally opposite the northern object. The mouse was returned to the open field for $5 \mathrm{~min}$ (T2). Mice failing to explore the objects were eliminated $(n=2)$. The percent time spent exploring the novel object was calculated for T2 (((time novel)/(time familiar + time novel) $) \times 100$ ). Successful spatial learning was defined as a mouse spending over $50 \%$ of its exploration with the novel placement object.

\section{Monitoring Activity}

Two days after the completion of object placement testing, mice were placed in the center of an open field Med Associates. Distance traveled was recorded for $60 \mathrm{~min}$ (Runker et al, 2011).

\section{Estrous Cycling}

Estrous cycling was conducted on a subset of adult female mice. Vaginal swabs were taken daily (0800-1000 hours) for 6 days, and stained with the Hema 3 Stain Set (Fisher 
Scientific). Estrous stage was determined following published criteria (Caligioni, 2009).

\section{Quantitative PCR}

Total brain RNA was prepared with a Trizol protocol and reverse transcribed using Moloney Murine Leukemia virus reverse transcriptase and oligo dT primer (New England Biolabs). Total SERT, distal SERT, and control gene (glyceraldehyde 3-phosphate dehydrogenase, Beta-glucuronidase, hypoxanthine phosphoribosyltransferase 1, and TATA binding protein) mRNA levels were measured in separate reactions via an ABI $7900 \mathrm{HT}$ real time-PCR thermal cycler using SYBR green detection of amplified fragments (Gyawali et al, 2010). Samples were reverse transcribed twice and each cDNA sample analyzed in quadruplicate. Details of primer sequences and cycling parameters are in Supplementary material.

\section{Statistics}

Comparisons of AL vs CR mice were performed using Student's $t$-test. ANOVA was used for analysis of diet by SERT genotype or diet by fluoxetine treatment comparisons with.

Additional details are available in the Supplementary material online.

\section{RESULTS}

\section{CR Enhances Fear Extinction Learning}

To assess whether CR altered fear learning and extinction during adolescence, postnatal day (P)36-38 female mice were diet restricted for one week (Figure 1a). CR reduced the body weight to about $80 \%$ of AL-fed mice (CR mean $13.0 \pm 0.3$, AL mean $16.2 \pm 0.8, p<0.01)$. Behavioral testing was begun after 8 days of CR as previous work has reported maximal anxiolytic effect of $\mathrm{CR}$ at this time (Yamamoto et al, 2009). Mice were fear conditioned followed by 2 days of fear extinction training. Groups did not show differences in fear acquisition (Figure 1b). CR mice showed enhanced fear extinction learning, with a greater reduction in freezing within session on day 1 of training (Figure $1 \mathrm{c}$ and $\mathrm{d}$, $p<0.01)$ and increased fear extinction retention over 2 days (Figure 1e, $p<0.01$ ).

Anxiety-like behavior was assessed using an elevated plus maze EPM 2 days after the mice completed fear extinction training. Consistent with studies in adult male mice (Yamamoto et al, 2009), CR adolescent females had decreased anxiety-like behavior, spending more time in the open arms than their AL littermates (Figure 1f, $p<0.05$ ).

\section{CR Enhances Extinction Learning in Adult Mice}

We tested adult mice to determine if the fear extinctionenhancing properties of $\mathrm{CR}$ were limited to adolescent females, and might explain the epidemiological distribution of anorexia nervosa (AN) (Hudson et al, 2007). Adults of both sexes showed enhanced fear extinction learning on the first day of fear extinction training with $C R$ (Figure $2 \mathrm{a}$ and $\mathrm{b}, p<0.01$ females; $p<0.01$ males). Females showed significant effects of CR on fear extinction retention (Figure 2c, $p<0.01$ ), while males showed a nonsignificant trend towards enhanced fear extinction retention (Figure 2d, NS).

\section{CR does not Increase General Activity}

To ensure differences in freezing patterns were not confounded by increased locomotor activity in CR mice, we assessed overall movement. In an activity box, CR mice did not show increased distance traveled per minute over a $1 \mathrm{~h}$ period $(\mathrm{AL}=111.1 \pm 2.8 \mathrm{~cm}, \mathrm{CR} 111.8 \pm 2.4 \mathrm{~cm}$, and $n=15,15$, NS). These results are consistent with previous studies showing no increase in activity with CR in C57BL/6 mice (Gelegen et al, 2007; Yamamoto et al, 2009).

\section{CR does not Improve Performance on an Object Placement Task}

To assess whether CR enhanced cognition in nonemotional contexts, we used an object placement task of spatial memory (Ennaceur and Aggleton, 1997). CR adult female mice did not spend significantly more time with the novel object than AL mice, meaning they did not display enhanced spatial learning $(\mathrm{AL}=61.1 \pm 4.5 \%, \mathrm{CR}=49.4 \pm 7.7 \%$, and $n=15,13$, NS).

\section{The Effects of CR on Estrous Cycles}

Ovarian hormones affect fear extinction learning, with increased estrogen enhancing consolidation of fear extinction learning (Lebron-Milad and Milad, 2012). We found CR treatment increased time spent in diestrus $(\mathrm{AL}=6.7 \% \pm 2.7$, $\mathrm{CR}=23.3 \% \pm 6.2, n=10,10, p<0.05$ ), as reported previously (Nelson et al, 1985), consistent with amenorrhea seen in AN as both are low estrogen states (Bailer and Kaye, 2003).

\section{CR does not Enhance Fear Extinction Learning in SERT KO Mice}

Because of the role of SERT in anxiety and fear extinction learning (Hartley et al, 2012; Wellman et al, 2007), we assessed whether the CR effect on extinction learning seen in wild-type mice would be altered in SERT knockout mice (Wellman et al, 2007). There was a significant effect of diet $\left(\mathrm{F}_{1,156}=15.74, p<0.001\right)$ and a trend towards and effect of SERT genotype $\left(\mathrm{F}_{1,156}=2.74, p=0.10\right)$ on fear extinction learning. There was an interaction between SERT genotype and dietary status $\left(\mathrm{F}_{1,156}=6.71, p=0.01\right)$. There were no differences in fear extinction learning between $\mathrm{CR}$ and $\mathrm{AL}$ female knockout mice for fear extinction learning on the first day (Figure 3a) or retention (Figure $3 b$ ). Although wild-type littermates that underwent $\mathrm{CR}$ continued to show enhanced fear extinction learning (Figure $3 a, p<0.001$ ), CR in SERT knockout mice did not enhance fear extinction learning $(p=0.56)$. The results were similar for fear extinction retention (Figure $3 \mathrm{~b}$ ). There was a main effect of diet $\left(\mathrm{F}_{1,156}=3.74, p=0.05\right)$ but not SERT genotype $\left(\mathrm{F}_{1,156}=0.82, p=0.37\right)$ on fear extinction retention with a diet $\times$ genotype interaction $\left(F_{1,156}=10.33, p=0.001\right)$. CR increased extinction retention in wild-type mice $(p<0.001)$, but had no effect in SERT knockout mice $(p=0.52)$. 
a Caloric restriction or ad libitum feeding

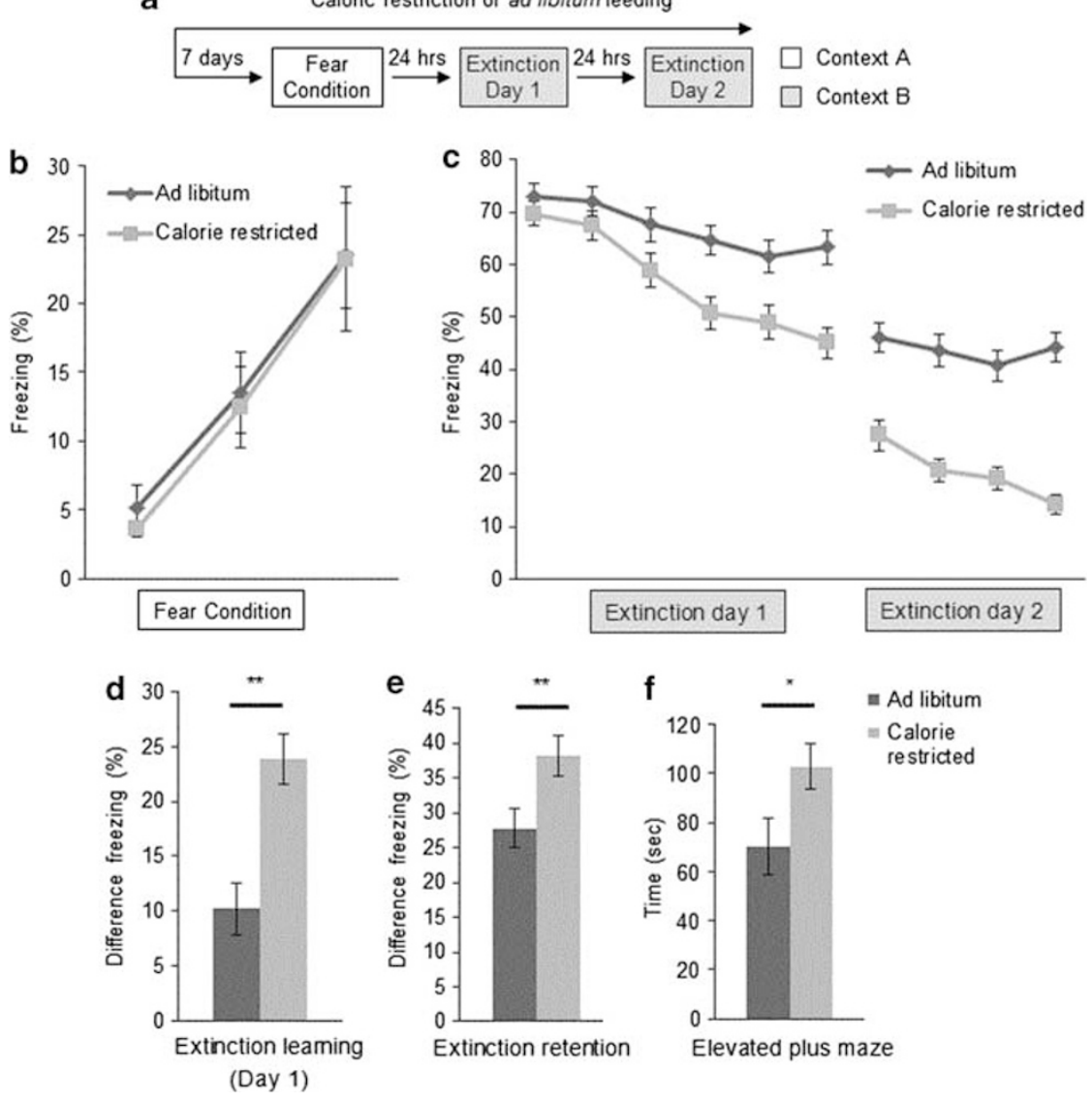

Figure I (a) Fear learning paradigm. CR began I week before fear conditioning, and was maintained throughout behavioral testing. (b) Adolescent female mice showed similar levels of freezing during acquisition during each of three tone-shock pairings $(n=10,10)$. (c) CR improved fear extinction learning on both days of extinction training in adolescent female mice. Each block represents three tones. Extinction day I shows all 6 bins; extinction day 2 shows first 4 bins, at which point the groups plateaued. (d) The degree of extinction on day I, as defined by the difference in freezing between tones $2-5$ and I5-I8, was significantly enhanced by CR $(n=22,25)$ as was (e) extinction retention, defined as the difference in freezing between tones $2-5$ on extinction day I and tones I-4 on extinction day $2(n=22,25)$. ( $f)$ CR also increased time spent in the open arm of the elevated plus maze $(n=28,28)$. Significance determined with Student's t-test. All results are presented as means \pm SEM. $* p<0.05, * * p \leqslant 0.01$.

\section{CR Increases the Distal Polyadenylation Fraction of SERT mRNA}

The SERT mRNA occurs in two alternative polyadenylation forms that differ by the presence or absence of a conserved sequence element in the $3^{\prime}$ untranslated region (Battersby et al, 1999; Gyawali et al, 2010). Increased expression of SERT mRNA containing the distal polyadenylation sequence appears associated with decreased anxiety. In particular, the distal polyadenylation fraction, the relative amount of total SERT mRNA that contains the distal polyadenylation sequence, is increased in mouse brain by chronic fluoxetine treatment (Hartley et al, 2012). To determine if CR induces similar changes in SERT expression, we quantified the SERT distal polyadenylation fraction using quantitative PCR. CR increased the distal polyadenylation fraction in a manner similar to our earlier fluoxetine results (Figure $4 \mathrm{a}, p<0.01$ ). CR did not change the level of total SERT mRNA relative to a panel of control genes (Figure 4b) consisting of glyceraldehyde 3-phosphate dehydrogenase, TATA binding protein, Beta-glucuronidase, and hypoxanthine phosphoribosyltransferase 1 . There were no significant differences in SERT expression between AL and $\mathrm{CR}$ mouse brain using any of the control genes to normalize for total mRNA or when all control genes were averaged.

\section{Fluoxetine Enhances Fear Extinction Retention in AL Fed Mice only}

SSRIs are anxiolytic drugs that improve fear extinction retention (Karpova et al, 2011). Given that fluoxetine and CR have similar effects on the expression of SERT mRNA species, and that the effects of CR on fear extinction appear to act through SERT, we hypothesized that fluoxetine would increase extinction retention in AL-fed mice, but not in CR mice. We compared the effects of these two treatments on fear extinction learning (Figure 5a) and retention (Figure 5b). Consistent with our a priori hypothesis, fluoxetine enhanced fear extinction retention in AL-fed mice but not CR mice $(p<0.05)$.

\section{DISCUSSION}

Adaptive fear responses are critical to the survival of organisms, allowing them to predict and avoid danger. Fear extinction is an active learning process that allows 
reassessment of cues of danger in response to a changing environment. In the absence of effective fear extinction, cues of safety that once predicted danger continue

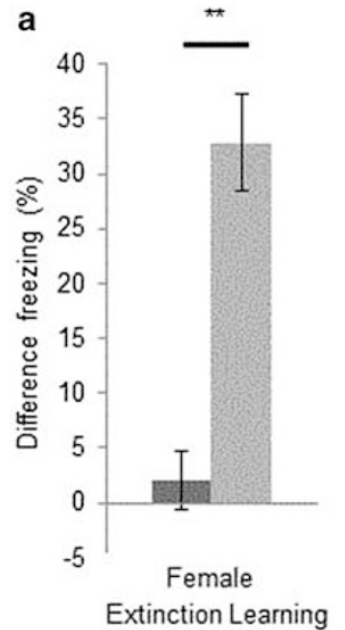

(Day 1)

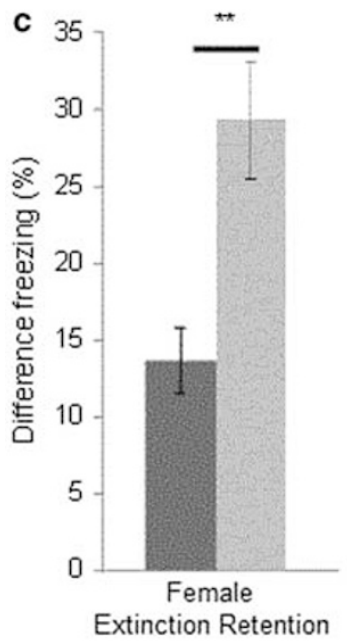

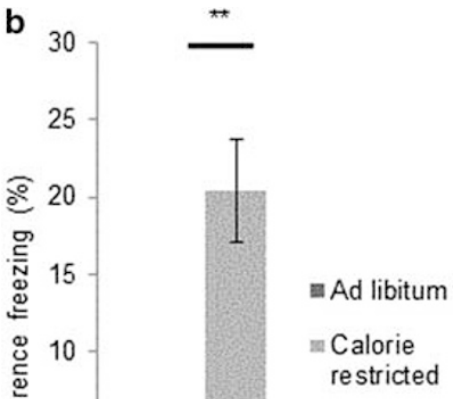

Figure 2 Effect of CR on the first day of extinction learning in adult mice. Extinction learning is improved in adult (a) females $(n=17,17)$ and (b) males $(n=|0,1|)$. Significance analyzed by Student's $t$-test. All results are presented as means \pm SEM. $* * * * \leqslant 0.01$. to elicit a fear response, and fearful associations can accumulate. In humans, inefficient fear extinction or inadequate retention of extinction learning are associated
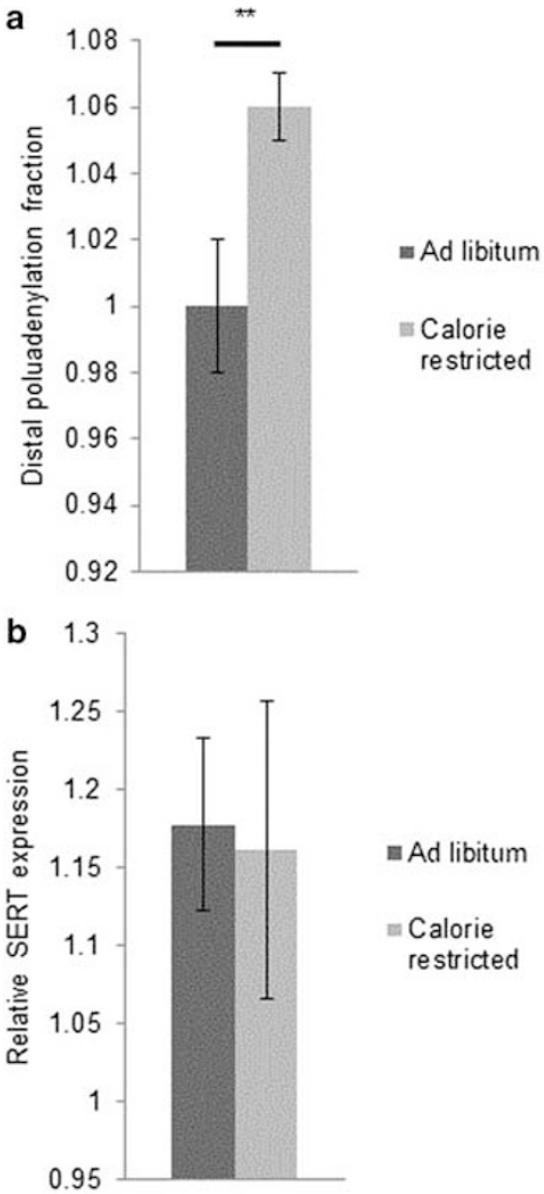

Figure 4 The effect of CR on SERT expression in adolescent female mouse brain. (a) CR increases the distal polyadenylation fraction (DPF) Brains of mice that had undergone CR $(n=4)$ had elevated levels of SERT mRNA containing the distal polyadenylation sequence than those of control animals $(n=4)$. $\mathrm{DPF}=$ relative amount of distal sequence containing SERT mRNATTotal SERT mRNA. (b) CR does not alter the expression of total SERT mRNA. Expression of the coding region of SERT mRNA was compared with a panel of four control genes in the brain from AL mice $(n=4)$ or CR mice $(n=4)$. Data presented is for the average of all four control genes. Differences assessed using Student's $t$-test. All results are presented as means \pm SEM. $* * * 0 \leqslant 0.01$.
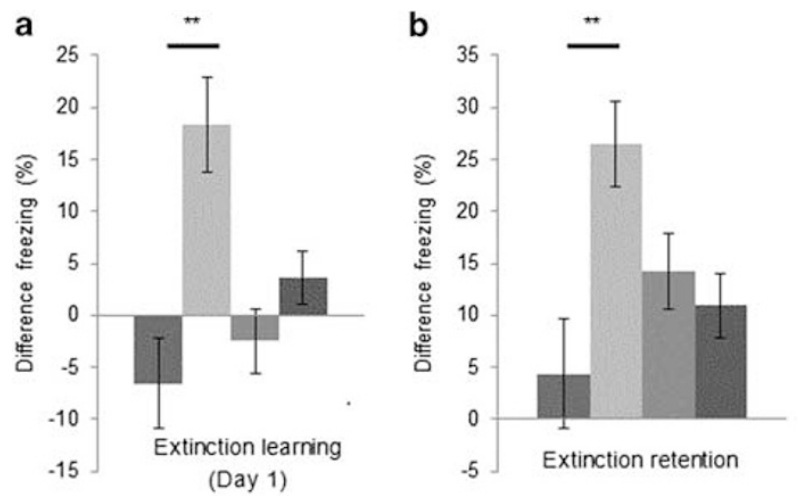

a Ad libitum SERT +/+

= Calorie restricted SERT $+/+$

$=$ Ad libitum SERT \%

- Calorie restricted SERT $\%$

Figure 3 Effect of CR on extinction learning and retention in mice lacking SERT. Neither (a) Day I extinction learning $(n=1 \mid, 12)$ or $(b)$ extinction retention over 2 days $(n=11,12)$ are improved in female SERT -1 - mice. Wild-type (SERT $+1+$ ) littermates showed improvements on both measures ((a) $n=8$, 9; (b) $n=8,9)$. Differences analyzed by ANOVA. All results are presented as means \pm SEM. $* * * \leqslant 0.01$. 

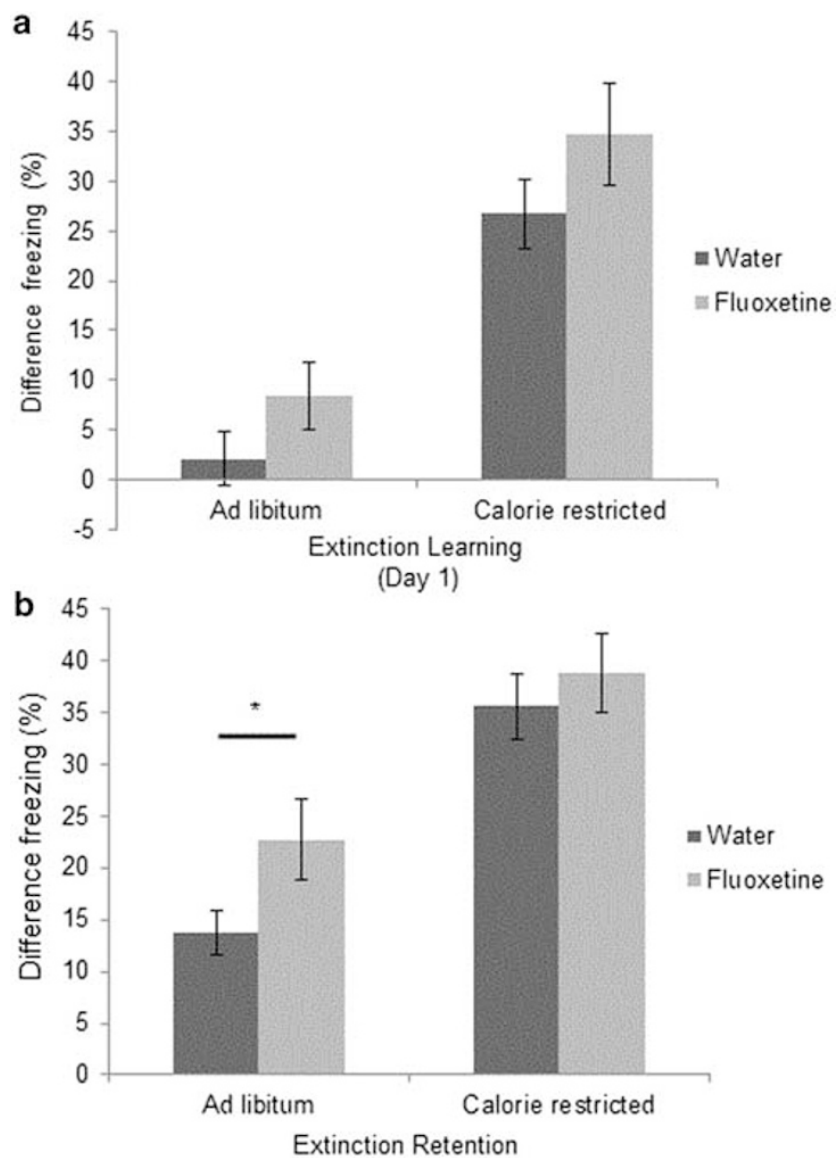

Figure 5 Effects of fluoxetine and CR on extinction leaming and retention. (a) Fluoxetine does not significantly improve extinction leaming on day one of extinction training in either $\operatorname{AL}(n=17,8)$ or $C R(n=17,7)$ mice. (b) Fluoxetine improves extinction retention in female AL mice $(n=17,8)$, but does not significantly increase extinction retention in CR mice $(n=17,7)$. Statistical significance analyzed using ANOVA with Fisher's least significant difference procedure. All results are presented as means \pm SEM. ${ }^{*} p<0.05$.

with avoidance, trait anxiety, and risk for anxiety disorders (Graham and Milad, 2011). Because adaptive fear responses are so central to survival, and reproductive success their neural substrates are highly conserved from rodent to human (LeDoux, 2012). This phylogenetic conservation means that studies of fear extinction are a useful translational approach to gain insight into human psychopathology. In this study we have implemented cued fear learning in calorie restricted and AL fed mice to determine the role of metabolic status in regulating adaptive fear responses. CR substantially enhances fear extinction learning and the ability of mice to retain extinction learning. These effects of CR are dependent on SERT as they are absent in knockout mice. SERT is further implicated in these effects of CR because individually SSRI's and CR induce similar enhancement of extinction retention, but when combined do not produce an additive effect. Finally, CR induces expression of a species of the mRNA for SERT that is associated with enhanced extinction retention and is also induced by chronic fluoxetine treatment.

SERT is a key molecule in regulating serotonergic neurotransmission that may represent a mechanistic link between anxiety, fear extinction learning, and CR. Mice lacking SERT display elevated anxiety-like behaviors and impaired fear extinction retention (Wellman et al, 2007). Decreased expression of SERT has been reported in individuals with anxiety disorders (Kang et al, 2010), which may contribute to impaired fear extinction learning reported in these disorders (Graham and Milad, 2011). Similarly, alterations in the serotonergic circuitry is seen in individuals with AN, a disorder characterized by CR (Kaye et al, 2003, 2009). Chronic treatment with fluoxetine enhances extinction learning and retention in mice, and these effects have been proposed to explain its anxiolytic properties (Karpova et al, 2011). In our studies, CR displayed SSRI-like effects on extinction learning and retention that were absent from mice lacking SERT. These results strongly implicate SERT as a mediator of the effects of CR on fear extinction. The underlying mechanism by which SERT regulates fear extinction learning is unclear, but the amygdala receives dense innervation from serotonergic raphe neurons, and iontophoretically applied serotonin reduces excitatory responses to glutamate in the lateral amygdala through the activation of GABAergic interneurons (Stutzmann and LeDoux, 1999). In addition, fluoxetine has also been shown to enhance neural plasticity through enhanced expression of BDNF (Karpova et al, 2011).

Both CR and chronic fluoxetine induce expression of the distal polyadenylation form of the SERT mRNA. The distal polyadenylation form of SERT is associated with enhanced fear extinction learning and decreased risk for panic disorder through a common polyadenylation polymorphism in the $3^{\prime}$ untranslated region of the human SERT gene (SLC6A4) (Hartley et al, 2012). In our studies there was no additive effect of $\mathrm{CR}$ and fluoxetine on fear extinction learning further suggesting that these two treatments act through similar mechanisms involving SERT. This is consistent with clinical data suggesting a limited role of SSRI treatment in individuals with $\mathrm{AN}$ at a low-weight state (Kaye et al, 2001).

Estrogen enhances fear extinction learning, which may explain its effects on emotion regulation. In our studies, CR increased the time mice spent in diestrus, a low estrogen phase of the mouse estrus cycle. At the same time, CR enhanced fear extinction learning suggesting that CR does not act primarily through its effects on the estrus cycle. Furthermore, male mice showed enhanced fear extinction learning within session with CR (Figure $2 b$ ).

The marked effects of $\mathrm{CR}$ on fear extinction learning may inform the pathophysiology of AN, in which there is both a high level of premorbid anxiety and subsequent weight loss. Lifetime comorbid anxiety disorders are as high as $83 \%$, and, in $75 \%$ of these individuals, anxiety precedes the onset of diet restriction (Godart et al, 2000). Individuals with AN have decreased tolerance for uncertainty and are thought to attempt to mitigate this perceived lack of control over life stressors through excessive control of food and weight as a way to reduce their anxiety (Frank et al, 2012). Furthermore, previous literature suggests that, in individuals with AN, eating may induce dysphoria while dietary restriction decreases anxiety (Kaye et al, 2009). Thus, CR is seen as a form of emotional regulation in AN (Espeset et al, 2012; Wildes et al, 2010). Treatment of the underlying anxiety as a central component to $\mathrm{AN}$ has gained increasing interest clinically. Recently, it was proposed that the therapeutic 
success of family-based therapy, which has shown promising results in the treatment of adolescents, centers on the use of exposure therapy, shown to be efficacious in the treatment of other anxiety disorders (Hildebrandt et al, 2012). Premeal anxiety has been seen to be inversely correlated with caloric intake in acutely weight restored individuals with AN (Steinglass et al, 2010), with mealbased exposure therapy being associated with a change in anxiety significantly associated with caloric intake (Steinglass et al, 2007, 2012).

Anxiety is accompanied by sensitization of fear circuitry in AN. Functional MRI studies using disorder-relevant stimuli such as high calorie foods and distorted body images induce elevated amygdala reactivity in subjects with AN relative to healthy controls (Ellison et al, 1998; Joos et al, 2011); positron emission tomography studies show hypoperfusion of structures associated with fear extinction-namely the medial prefrontal cortex-and hyperperfusion of the amygdala - hippocampal complex in AN (Takano et al, 2001). Consistent with this clinical perspective, our results suggest that CR may normalize dysregulated fear responses in $\mathrm{AN}$, which in combination with trait or acquired alterations in cortico-striatal circuit function that have been described in $\mathrm{AN}$, may help explain why dieting behavior is so vigorously reinforced as well as the high comorbidity of anorexia with obsessive-compulsive disorder (Milad and Rauch, 2012; Wagner et al, 2007; Zheng et al, 2012).

Our present findings provide motivation to study conditioned-fear responses directly in individuals with AN as an important factor in the rapid, tenacious, and potentially dangerous reinforcement of dieting behavior seen in the disorder. Further studies of conditioned-fear responses in nonhuman systems may lead to a more precise mechanistic understanding of the biological effects of CR in AN and potentially lead to improved treatments.

\section{ACKNOWLEDGEMENTS}

We thank F Lee and J Steinglass for assistance in the design of experiments, interpretation of results, and reviewing this manuscript. This work was supported by The Hartwell Foundation (CEG), National Institute of Health Medical Scientist Training Program grant GM07739 (MCR), and the National Institutes of Mental Health (P50 MH62196 to BJC).

\section{DISCLOSURE}

The authors declare no conflict of interest.

\section{REFERENCES}

Bailer UF, Kaye WH (2003). A review of neuropeptide and neuroendocrine dysregulation in anorexia and bulimia nervosa. Curr Drug Targets CNS Neurol Disord 2: 53-59.

Battersby S, Ogilvie AD, Blackwood DH, Shen S, Muqit MM, Muir WJ et al (1999). Presence of multiple functional polyadenylation signals and a single nucleotide polymorphism in the $3^{\prime}$ untranslated region of the human serotonin transporter gene. J Neurochem 72: 1384-1388.

Bengel D, Murphy DL, Andrews AM, Wichems CH, Feltner D, Heils A et al (1998). Altered brain serotonin homeostasis and locomotor insensitivity to 3, 4-methylenedioxymethamphetamine ('Ecstasy') in serotonin transporter-deficient mice. Mol Pharmacol 53: 649-655.

Caligioni CS (2009). Assessing reproductive status/stages in mice. Current protocols in neuroscienceleditorial board, Jacqueline N. Crawley... [et al.] Appendix 4: Appendix 4I.

Chen ZY, Jing D, Bath KG, Ieraci A, Khan T, Siao CJ et al (2006). Genetic variant BDNF (Val66Met) polymorphism alters anxietyrelated behavior. Science 314: 140-143.

Ellison Z, Foong J, Howard R, Bullmore E, Williams S, Treasure J (1998). Functional anatomy of calorie fear in anorexia nervosa. Lancet 352: 1192.

Ennaceur A, Aggleton JP (1997). The effects of neurotoxic lesions of the perirhinal cortex combined to fornix transection on object recognition memory in the rat. Behav Brain Res 88: 181-193.

Espeset EM, Gulliksen KS, Nordbo RH, Skarderud F, Holte A (2012). The link between negative emotions and eating disorder behaviour in patients with anorexia nervosa. European Eating Disorders Review: The Journal of the Eating Disorders Association 20: 451-460.

Frank GK, Roblek T, Shott ME, Jappe LM, Rollin MD, Hagman JO et al (2012). Heightened fear of uncertainty in anorexia and bulimia nervosa. Int J Eat Disord 45: 227-232.

Gelegen C, Collier DA, Campbell IC, Oppelaar H, van den Heuvel J, Adan RA et al (2007). Difference in susceptibility to activitybased anorexia in two inbred strains of mice. European Neuropsychopharmacology: The Journal of the European College of Neuropsychopharmacology 17: 199-205.

Godart NT, Flament MF, Lecrubier Y, Jeammet P (2000). Anxiety disorders in anorexia nervosa and bulimia nervosa: co-morbidity and chronology of appearance. European Psychiatry: The Journal of the Association of European Psychiatrists 15: 38-45.

Graham BM, Milad MR (2011). The study of fear extinction: implications for anxiety disorders. Am J Psychiatry 168: $1255-1265$.

Gyawali S, Subaran R, Weissman MM, Hershkowitz D, McKenna MC, Talati A et al (2010). Association of a polyadenylation polymorphism in the serotonin transporter and panic disorder. Biol Psychiatry 67: 331-338.

Hartley CA, McKenna MC, Salman R, Holmes A, Casey BJ, Phelps EA et al (2012). Serotonin transporter polyadenylation polymorphism modulates the retention of fear extinction memory. Proc Nat Acad Sci Usa 109: 5493-5498.

Hildebrandt T, Bacow T, Markella M, Loeb KL (2012). Anxiety in anorexia nervosa and its management using family-based treatment. European Eating Disorders Review: The Journal of the Eating Disorders Association 20: e1-16.

Hudson JI, Hiripi E, Pope HG Jr, Kessler RC (2007). The prevalence and correlates of eating disorders in the National Comorbidity Survey Replication. Biol Psychiatry 61: 348-358.

Joos AA, Saum B, van Elst LT, Perlov E, Glauche V, Hartmann A et al (2011). Amygdala hyperreactivity in restrictive anorexia nervosa. Psychiat Res 191: 189-195.

Kang EH, Shim HB, Kim KJ, Park JE, Lee IS, Yu BH (2010). Platelet serotonin transporter function after short-term paroxetine treatment in patients with panic disorder. Psychiat Res 176: 250-253.

Kaplan GB, Moore KA (2011). The use of cognitive enhancers in animal models of fear extinction. Pharmacol Biochem Behav 99: 217-228.

Karpova NN, Pickenhagen A, Lindholm J, Tiraboschi E, Kulesskaya N, Agustsdottir A et al (2011). Fear erasure in mice requires synergy between antidepressant drugs and extinction training. Science 334: 1731-1734.

Kaye WH, Barbarich NC, Putnam K, Gendall KA, Fernstrom J, Fernstrom $\mathrm{M}$ et al (2003). Anxiolytic effects of acute tryptophan depletion in anorexia nervosa. Int J Eat Disord 33: 257-267 discussion 268-270. 
Kaye WH, Fudge JL, Paulus M (2009). New insights into symptoms and neurocircuit function of anorexia nervosa. Nat Rev Neurosci 10: $573-584$

Kaye WH, Nagata T, Weltzin TE, Hsu LK, Sokol MS, McConaha C et al (2001). Double-blind placebo-controlled administration of fluoxetine in restricting- and restricting-purging-type anorexia nervosa. Biol Psychiatry 49: 644-652.

Lebron-Milad K, Milad MR (2012). Sex differences, gonadal hormones and the fear extinction network: implications for anxiety disorders. Biology of Mood \& Anxiety Disorders 2: 3.

LeDoux JE (2012). Evolution of human emotion: a view through fear. Prog Brain Res 195: 431-442.

Mao SC, Hsiao YH, Gean PW (2006). Extinction training in conjunction with a partial agonist of the glycine site on the NMDA receptor erases memory trace. The Journal of Neuroscience: The Official Journal of the Society for Neuroscience 26: 8892-8899.

Maron E, Kuikka JT, Shlik J, Vasar V, Vanninen E, Tiihonen J (2004). Reduced brain serotonin transporter binding in patients with panic disorder. Psychiat Res 132: 173-181.

Maya Vetencourt JF, Sale A, Viegi A, Baroncelli L, De Pasquale R, O'Leary OF et al (2008). The antidepressant fluoxetine restores plasticity in the adult visual cortex. Science 320: 385-388.

Milad MR, Rauch SL (2012). Obsessive-compulsive disorder: beyond segregated cortico-striatal pathways. Trends Cogn Sci 16: $43-51$.

Monfils MH, Cowansage KK, Klann E, LeDoux JE (2009). Extinction-reconsolidation boundaries: key to persistent attenuation of fear memories. Science 324: 951-955.

Murrough JW, Huang Y, Hu J, Henry S, Williams W, Gallezot JD et al (2011). Reduced amygdala serotonin transporter binding in posttraumatic stress disorder. Biol Psychiatry 70: 1033-1038.

Nelson JF, Gosden RG, Felicio LS (1985). Effect of dietary restriction on estrous cyclicity and follicular reserves in aging C57BL/6J mice. Biol Reprod 32: 515-522.

Reimold M, Smolka MN, Zimmer A, Batra A, Knobel A, Solbach C et al (2007). Reduced availability of serotonin transporters in obsessive-compulsive disorder correlates with symptom severity-a [11C]DASB PET study. J Neural Transm 114: $1603-1609$.

Runker AE, O'Tuathaigh C, Dunleavy M, Morris DW, Little GE, Corvin AP et al (2011). Mutation of Semaphorin-6A disrupts limbic and cortical connectivity and models neurodevelopmental psychopathology. PloS One 6: e26488.

Soliman F, Glatt CE, Bath KG, Levita L, Jones RM, Pattwell SS et al (2010). A genetic variant BDNF polymorphism alters extinction learning in both mouse and human. Science 327: 863-866.
Sotres-Bayon F, Bush DE, LeDoux JE (2007). Acquisition of fear extinction requires activation of NR2B-containing NMDA receptors in the lateral amygdala. Neuropsychopharmacology: Official Publication of the American College of Neuropsychopharmacology 32: 1929-1940.

Spolidoro M, Baroncelli L, Putignano E, Maya-Vetencourt JF, Viegi A, Maffei L (2011). Food restriction enhances visual cortex plasticity in adulthood. Nature Communications 2: 320 .

Steinglass J, Albano AM, Simpson HB, Carpenter K, Schebendach J, Attia E (2012). Fear of food as a treatment target: exposure and response prevention for anorexia nervosa in an open series. Int $J$ Eat Disord 45: 615-621.

Steinglass J, Sysko R, Schebendach J, Broft A, Strober M, Walsh BT (2007). The application of exposure therapy and D-cycloserine to the treatment of anorexia nervosa: a preliminary trial. J Psychiatr Pract 13: 238-245.

Steinglass JE, Sysko R, Mayer L, Berner LA, Schebendach J, Wang $\mathrm{Y}$ et al (2010). Pre-meal anxiety and food intake in anorexia nervosa. Appetite 55: 214-218.

Stutzmann GE, LeDoux JE (1999). GABAergic antagonists block the inhibitory effects of serotonin in the lateral amygdala: a mechanism for modulation of sensory inputs related to fear conditioning. The Journal of Neuroscience: The Official Journal of the Society for Neuroscience 19: RC8.

Takano A, Shiga T, Kitagawa N, Koyama T, Katoh C, Tsukamoto E et al (2001). Abnormal neuronal network in anorexia nervosa studied with I-123-IMP SPECT. Psychiat Res 107: 45-50.

Wagner A, Aizenstein H, Venkatraman VK, Fudge J, May JC, Mazurkewicz L et al (2007). Altered reward processing in women recovered from anorexia nervosa. Am J Psychiatry 164: 1842-1849.

Wellman CL, Izquierdo A, Garrett JE, Martin KP, Carroll J, Millstein $\mathrm{R}$ et al (2007). Impaired stress-coping and fear extinction and abnormal corticolimbic morphology in serotonin transporter knock-out mice. The Journal of Neuroscience: The Official Journal of the Society for Neuroscience 27: 684-691.

Wildes JE, Ringham RM, Marcus MD (2010). Emotion avoidance in patients with anorexia nervosa: initial test of a functional model. Int J Eat Disord 43: 398-404.

Yamamoto Y, Tanahashi T, Kawai T, Chikahisa S, Katsuura S, Nishida $\mathrm{K}$ et al (2009). Changes in behavior and gene expression induced by caloric restriction in C57BL/6 mice. Physiol Genomics 39: 227-235.

Zheng D, Cabeza de Vaca S, Carr KD (2012). Food restriction increases acquisition, persistence and drug prime-induced expression of a cocaine-conditioned place preference in rats. Pharmacol Biochem Behav 100: 538-544.

Supplementary Information accompanies the paper on the Neuropsychopharmacology website (http://www.nature.com/npp) 